\title{
Bone tissue regeneration: biology, strategies and interface studies
}

\author{
Mojtaba Ansari ${ }^{1}$
}

Received: 2 August 2019 / Accepted: 15 November 2019 / Published online: 25 November 2019

(c) The Author(s) 2019

\begin{abstract}
Nowadays, bone diseases and defects as a result of trauma, cancers, infections and degenerative and inflammatory conditions are increasing. Consequently, bone repair and replacement have been developed with improvement of orthopedic technologies and biomaterials of superior properties. This review paper is intended to sum up and discuss the most relevant studies performed in the field of bone biology and bone regeneration approaches. Therefore, the bone tissue regeneration was investigated by synthetic substitutes, scaffolds incorporating active molecules, nanomedicine, cell-based products, biomimetic fibrous and nonfibrous substitutes, biomaterial-based three-dimensional (3D) cell-printing substitutes, bioactive porous polymer/inorganic composites, magnetic field and nano-scaffolds with stem cells and bone-biomaterials interface studies.
\end{abstract}

Keywords Bone regeneration $\cdot$ Biology $\cdot$ Biomaterials $\cdot$ Biocompatibility $\cdot$ Tissue engineering

\section{Introduction}

Bone presents numerous performs including principal backing structure designed formation, the binding place for muscles, ligaments and tendons, mechanical support and shield of most important tissues (Pajarinen et al. 2019). Besides, hematopoiesis and vital mineral materials are provided by bone marrow structure (Ansari et al. 2011). Musculoskeletal diseases including rheumatoid arthritis, osteoarthritis, osteoporosis, low back pain and limb trauma are all commonly developing and painful (Roshanbinfar and Ansari 2013). Most bone fractures occur as a result of inconvenient or incompetent bone regeneration (Naghib et al. 2012). Large segmental bone fractures did not repair instinctively and require orthopedic operation. Furthermore, spinal fusion surgeries may result in non-union frequently (Eslami et al. 2018). Approximately bone defects are currently cured using bone autograft (the gold standard for surgeons), allografts and biomaterial substitutes with biocompatible, osteointegrative "intense communications among the host bone tissue and the substituted materials", osteoconductive "the ability of materials to be colonized by host bone cells and blood vessels" and osteoinductive "motivate host mesenchymal

Mojtaba Ansari

ansari@meybod.ac.ir; amirmojtaba26@gmail.com

1 Department of Biomedical Engineering, Meybod University, Meybod, Iran stem cells from encompassing tissues to differentiate to bone cells" properties (Sheikh et al. 2019). Autografts, coupled with difficulties, come across post-surgery containing nerve injury, infections, morbidity and chronic pain at the donor or acceptor site. Besides, allografts have the potential of disease conduction, infection and incite immune reactions following the implant rejection. Investigators have attempted to solve these complications of bone grafts by means of natural or synthetic biomaterials (Ansari and Eshghanmalek 2019).

This study concentrates on bone biology, bone tissue regeneration strategies including synthetic substitutes alone, scaffolds combined with active molecules, nanomedicine for healing of bone trauma and defects, cell-based combination products with cells from various sources, biomimetic fibrous and nonfibrous substitutes, biomaterial-based threedimensional (3D) cell-printing substitutes, bioactive porous polymer/inorganic composite and magnetic field and nanoscaffolds with stem cells, bone biomaterial interface studies. The interactions between bone cells and biomaterials, as they play a crucial role in bone repair.

\section{Bone biology}

\section{Bone structure}

Bone is not homogeneously solid, but it is arranged of living bone cells set in a biomineral medium. Actually, bone is 
designed by the toughening of this medium nearby entangled cells. Bone itself involves chiefly of collagen fibers and an inorganic bone mineral in the form of small crystals (Uskokovic et al. 2019).

\section{Bone cells and matrix}

The biomineral medium of bone contains about $30 \%$ organic and $70 \%$ inorganic segments (Wang et al. 2019). Almost, $90 \%$ of this organic segment is collagen, whereas the residual $10 \%$ was mostly non-collagenous proteins, lipids, proteoglycan molecules, osteopontin (OPN), and other bone matrix proteins (Hu et al. 2019). The bone matrix proteins play vital role in mechanical strength and tissue adhesive characteristics. Principally, the mineral phase of bone is hexagonal hydroxyapatite (HA) crystal (Qiu et al. 2019). The chemical formula of crystalline $\mathrm{HA}$ is $\mathrm{Ca}_{10}\left(\mathrm{PO}_{4}\right)_{6}(\mathrm{OH})_{2}$ (Türk et al. 2019), where surface binding and electrostatic interactions are related to presence of $\mathrm{Ca}^{2+}$ and $\left(\mathrm{PO}_{4}\right)^{3-}$ (Samavedi et al. 2013). The HA crystals are organized parallel to the long axes of collagen fibers by self-assembly of collagen triple helices (Wang et al. 2012).

\section{Bone cells}

Further to mineralized bone milieus, bone cells are additionally critical to the function of bones. Bone is responsible for several roles in the body containing mechanical functions (protection, shape, movement and locomotion), synthetic functions (synthesis of blood cells) and metabolic functions (mineral storage, regulation of calcium and phosphate, fat storage and role in acid-base balance). The four most important cells including: osteogenic, osteoblasts, osteocytes, and osteoclasts (together recognized as the basic multicellular unit (BMU)) contained in bone regeneration and structure are shown in Fig. 1 (Kular et al. 2012).

Osteoblasts are derived from osteoprogenitor cells of mesenchymal origin in bone marrow and other connective tissues. They are differentiated and proliferated to osteoblasts before bone formation, stimulated through bone morphogenetic proteins (BMPs). These cells are responsible for growing or remodeling of bone (Standring 2016). Also, their roles are the synthesis, deposition and mineralization of the bone matrix by producing a protein mixture called osteoid. Mature osteoblasts may convert to a layer of cuboidal cells, that they can undergo apoptosis or become osteocytes and bone-lining cells (Sikavitsas et al. 2001).

Osteocytes are the most abundant cell type in bone tissue (Noble and Reeve 2000). They are described by a starshaped morphology. Osteocytes are derived from MSCs that undergo osteoblastic differentiation. These are inactive osteoblasts that have become trapped in the bone that they have created. They maintain connections to other osteocytes and osteoblasts. They are vital for communication within bone tissue. Furthermore, osteocytes have been presented to react to several biochemical signaling paths and contribute to regulation of calcium and phosphate homeostasis. Malfunction of the osteocyte cells growths leads to bone brittleness and may result in osteoporosis (Standring 2016; Teti 2011).

Bone-lining cells are inactive osteoblasts that reside on bony surfaces (Franz Odendaal et al. 2006). Lining cells play
Fig. 1 Four types of cells are found within bone tissue including osteogenic cells, osteocytes, osteoclasts, and osteoblast (Behzadi et al. 2017)

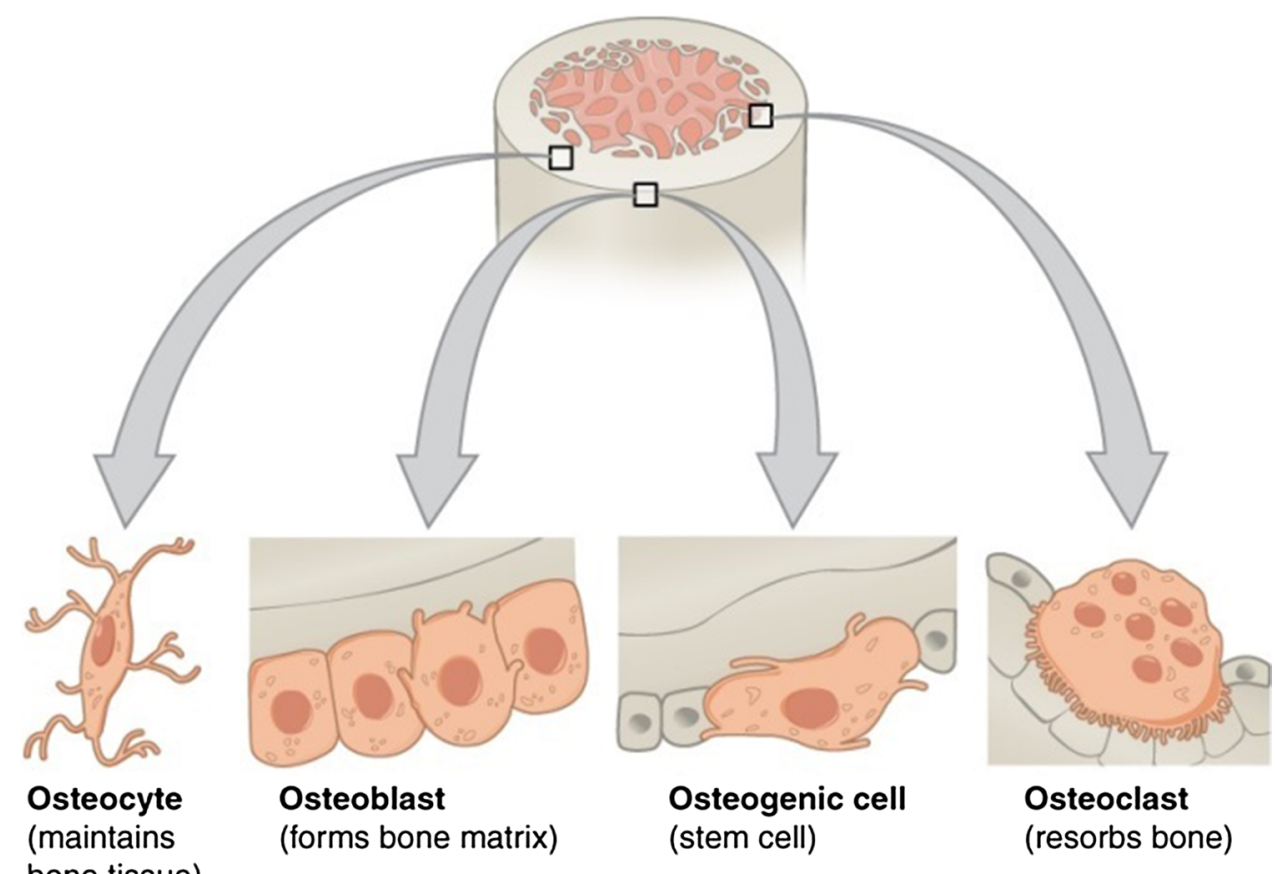


a significant role in coupling bone resorption to bone formation and in calcium hemostasis and in osteoclastic differentiation. They also act as hurdle that avoids direct interface among osteoclasts and bone matrix (Luginbuehl et al. 2004).

Osteoclasts are large cells with more than one nucleus that are differentiated from the hematopoietic lineage. Their job is to break down bone (Boyle et al. 2003). They release enzymes and acids to dissolve minerals in bone and digest them. This process is called resorption. Osteoclasts help remodel injured bones and create pathways for nerves and blood vessels to travel through. Irregularities in osteoclastic activity distinguish diseases such as osteoporosis (increased osteoclast activity) and osteopetrosis (Kular et al. 2012; Standring 2016).

\section{Mechanism of bone repair}

Bone fracture regeneration is a multipart, arranged, reformative procedure that contains a vital numeral of progenitor cells along with inflammatory, endothelial and hematopoietic cells. The bone restorative procedure has three intersecting phases: inflammation, bone production and bone remodeling (Schindeler et al. 2008). Inflammation begins instantly once the bone is broken and continues for more than a few days. As soon as the bone is broken, there is bleeding into the region, result in inflammation and coagulation of blood at the breakage location (Sikavitsas et al. 2001). This is responsible for the primary fundamental strength and basis for new bone formation. Bone production initiates once the coagulated blood formed by inflammation is substituted with fibrous tissue and cartilage (recognized as soft callus). As regeneration growths, the soft callus is switched with hard bone (identified as hard callus), which is noticeable on X-rays some weeks after the fracture. Bone remodeling, the ultimate stage of bone healing, continue more than a few months. In regeneration, bone regenerates to form and converts condensed, returning to its original form (Dimitriou et al. 2005). Furthermore, blood circulation in the region progresses. Once suitable bone restorative has followed, weight bearing inspires bone healing. Briefly, the stages of bone fracture repair are presented in Fig. 2.

\section{Bone regeneration strategies}

At present, the "conventional standard" healing of patients suffering from long or imperfect bone treatment is to implement bone grafting, by means of either an autograft or an allograft. Though, there are problems to bone grafting. Subsequently, a more maintainable, long-term healing plan is necessary. To that end, bone graft replacements are being concocted to aid damaged fracture treatment. Based on the gravity of the trauma, the main strategies are established for bone repair:

1. Synthetic substitutes alone

2. Scaffolds combined with active molecules

3. Nanomedicine for healing of bone trauma and defects

4. Cell-based combination products with cells from various sources

5. Biomimetic fibrous and nonfibrous substitutes

6. Biomaterial-based 3D cell-printing substitutes

7. Bioactive porous polymer/inorganic composite

8. Magnetic field and nano-scaffolds with stem cells.
Fig. 2 Stages of bone fracture repair and remodeling

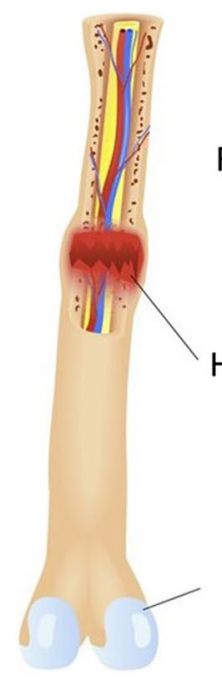

Hematoma formation

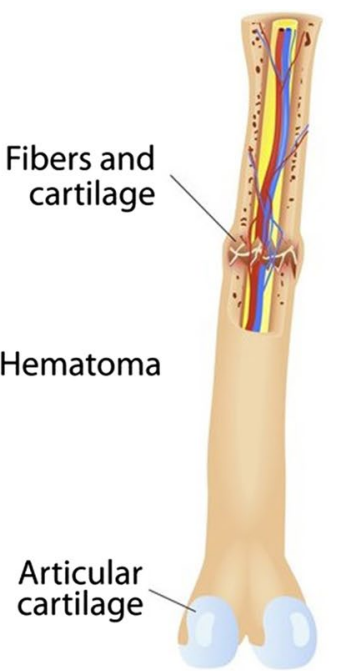

Fibrocartilaginous callus formation

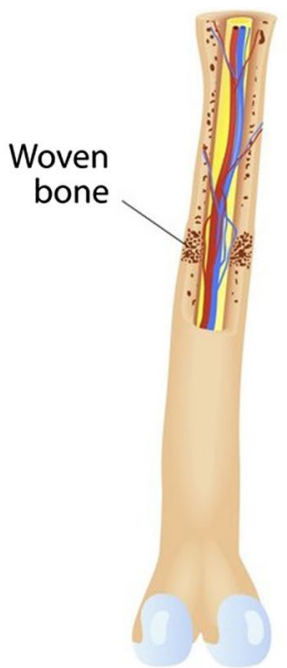

Bony callus formation

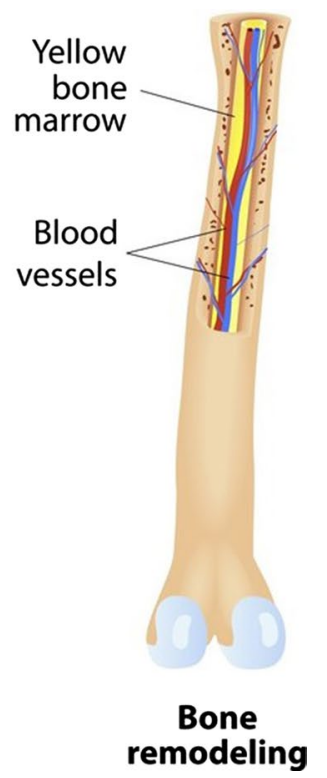




\section{Suitable material selection of damaged bone substitute}

Demineralized bone matrix (DBM) was produced with osteoconductive and osteoinductive properties (Giannoudis et al. 2005). The preferred choice for DBM synthesis was reported cortical bone as a result of osteoinductive with a lesser antigenic possibility in comparison to cancellous bone (Burg et al. 2000). Utilization of viscous spongy cellulose revealed that it was extremely suitable for bone regeneration. The implanted cellulose in the femoral bone of rats showed that osteoconduction was mostly happened (Ekholm et al. 2005). Recently, bacteria strains secretion-derived bacterial cellulose was introduced as an emerging player in tissue engineering because of its extremely good cytocompatibility and physiochemical properties. Therefore, its modified compounds were used for bone regeneration (Stumpf et al. 2018). Synthetic media have similarly been evaluated as acellular bone tissue engineering materials. Hence, polyL-lactide (PLLA) films were used to repair 1-cm trauma in the radius bone of mature rabbits, and histologic results indicated that the cortical bone was redeveloped over the defect (Zhang et al. 2006). Poly- $\varepsilon$-caprolactone-co-lactide was used as a different potential filler material in bone defect, and investigated in non-osseous usage. To evaluate the absorption and biocompatibility of this copolymer, it was used in femoral defect of rat (Helminen et al. 2002). Photocrosslinkable polyanhydrides constituents demonstrated the convinced benefits for orthopedic regeneration. In this case, the photopolymerizable component enhanced microfabrication probability of porous scaffolds. Also, mechanical investigations proved reliability of these polymers for tissue engineering applications (Pakulska 2016). Calcium phosphate and silicate-based bioceramics were prominently featured among used biomaterials for bone regeneration (Samavedi et al. 2013; Diba et al. 2014; Dziadek et al. 2017). For example, nanostructured monticellite $\left(\mathrm{CaMgSiO}_{4}\right)$ ceramic and its composites (with HA) showed good in vitro bioactivity, biocompatibility, and antibacterial properties for bone tissue engineering application (Chen et al. 2008; Kalantari et al. 2017; Kalantari et al. 2018a, b, c, 2019; Kalantari and Naghib 2019).

\section{Scaffolds combined with active biomolecules}

The approaches can be categorized in three classifications: (a) application of recombinant growth factors and a combination of growth factors associated with a natural medium or calcium phosphate substantial carrier, (b) application of proteins to target cellular receptors, and (c) application of small molecules that target the signaling pathway (Ansari et al. 2018). Figure 3 presents the general schematic presentation of the scaffold loaded with active biomolecules for accelerate bone repair. The main growth factors have already been used in clinics included BMP-2, BMP-7, and rhPGDFBB (Ho-Shui-Ling et al. 2018). The growth factors effect on bone progenitors by interrelating with their particular receptors, which activate the chemical signaling pathways result in bone development. Several studies have previously been done on BMP-2 associated with a type I collagen porous structure as delivery service, for application in open tibial fractures and in spinal defects (Bessa et al. 2008). In a study, it is combined with a titanium or PEEK structure for application in anterior lumbar interbody fusion (Vaidya et al. 2008). It is well known that bone restoration in response to BMP-2 is dose dependent. High doses of BMP-2 may result in osteolysis. So, the potent activating characteristic of bone repair of BMP-2 needs to be further optimized (Bruder et al. 1994). Latest documents in a rat femoral bone fracture, applied PLGA as a polymeric carrier as a nano reservoir for

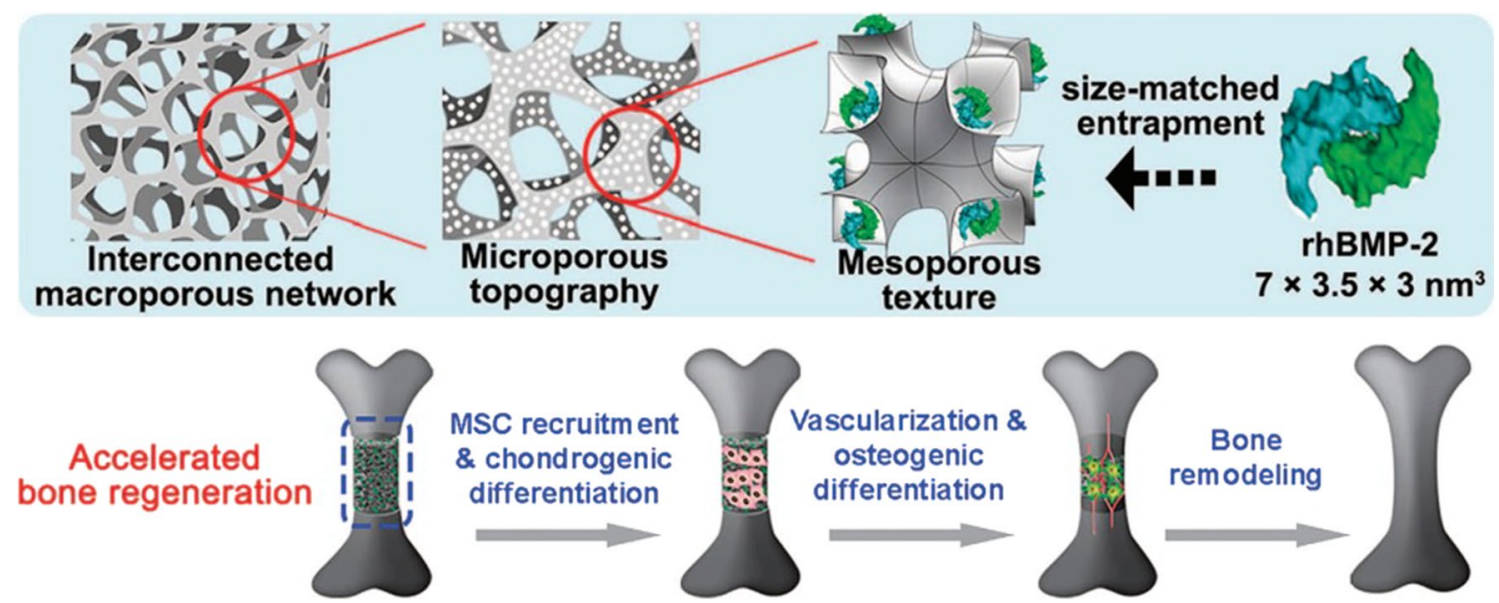

Fig. 3 Schematic presentation of macro/micro/nano-porous scaffold loaded with active biomolecules for accelerate bone regeneration (Yi et al. 2016) 
BMP-2 delivery (Zheng et al. 2010). The result revealed that it is conceivable to adjust the dose of BMP-2 in vivo. This controlled dose influenced the dimensions of bone formation, and enhanced the kinetics of bone renovation by means of delivery of BMP-2.

BMP-7 growth factor is osteoinductive which is studied for the clinical application (Bostrom and Seigerman 2005). Collagen type I incorporated with BMP-7 in the paste form is used for recalcitrant long bone and spine surgical treatment. Investigations on a sheep model indicated that the BMP-7 paste may be able to incorporate with a porous scaffold to initiate long bones regeneration (Haidar et al. 2009). rhPDGF-BB in form of device/drug product was employed for hindfoot and ankle fusion (Solchaga et al. 2012). PDGF, by functioning on PDGF receptors, motivates the employment, migration and proliferation of cells containing mesenchymal stem cells and stimulates the neovascularization by growing vascular endothelial cells at the location of bone repair.

Presently, a $\beta$-TCP/PDGF scaffold was employed to provide osteoconductivity for bone repair. In a study on patients devoted to hindfoot or ankle arthrodesis, healed with rhPDGF-BB/ $/$-TCP, gave rise to comparable fusion extents, minus pain, and less side effects in comparison to healing with autograft (Bateman et al. 2005).

Other growth factors like GDF-5 are kind of BMP group that encourages bone formation (Nickel et al. 2005). Several researches have confirmed rhGDF-5 has the potential of bone induction tissue growth. A bone substitute rhGDF-5/ $(\beta-\mathrm{TCP})$ was applied for dental implants and medical cure of periodontal syndrome. The in vitro results indicating that rhGDF-5 has the potential to promote gene expression and production of the ECM proteins such as collagen type II and aggrecan (Poehling et al. 2006).

Peptides, they have the ability to access cellular receptors, are substitutes for recombinant growth factors which are able to produce easily. Bioactive B2A (B2A2-K-NS) synthetic polypeptide applied to augment spinal fusion (Omrani et al. 2016). HAP/ $\beta$-TCP incorporated with $B 2 A$ granules were investigated for foot and ankle fusion.

In vitro results indicate that $\mathrm{B} 2 \mathrm{~A}$ induces chondrogenic differentiation and improves the in vivo healing of injured cartilage in an osteoarthritis model (Ho-Shui-Ling et al. 2018). Collagen is a major protein of the ECM and contributes in osteoblast attachment and activity (Ansari and Moztarzadeh 2012). P-15 is a 15 amino-acid protein obtained from collagen and promotes the differentiation of mesenchymal stem cells. P-15 has been applied in combination with bone inorganic for spinal fusion, non-union fractures and joint reconstruction with acceptable results (Bhatnagar et al. 1999). Besides, small molecules applied as controllers of bone bulk. Parathyroid hormone has a vital character in controlling calcium phosphate digestion. PTH entrapped in a normal fibrin medium, incorporated with a mechanical ceramic constituent (HAP/TCP granules), may be responsible for structural stability and osteoconduction for the period of healing (Portale et al. 1984).

Microorganism-derived polyhydroxyalkanoate (PHA) scaffolds have emerged as polymeric promising biomaterials with excellent potential for bone tissue engineering applications because of their good biodegradability, biocompatibility and vascularization, and unique physiochemical properties. They induced cell adhesion and growth on their porous structure for bone regeneration (Lim et al. 2017). Lalzawmliana et al. (2019) reported that mesoporous bioactive glass (MGB) scaffolds as third-generation biomaterials were used for regeneration of critical bone defects, and MGB scaffolds should have large interconnected pores for improving growth, adhesion and proliferation of osteoblast cells and assisting in angiogenesis. In recent studies, effect of threedimensional (3D) scaffolds and their fibrous order on biocompatibility were investigated. The results showed that 3D aligned nanofibrous scaffolds provided cell behaviors better than two-dimensional (2D) scaffolds, because of their more accommodation for the attached cells, and loading more bioactive molecules for promotion of cell growth, proliferation, migration and differentiation. Nevertheless, a big challenge was mentioned for them that related to their static status. For example, they cannot remodel their stiffness, surface chemistry and roughness in an in situ and dynamic situation, so cannot mimic the function of main tissue (Jin et al. 2018). Rather et al. reviewed the dual functional strategies to spread osteogenesis coupled angiogenesis through different scaffolds. Vascularization played the important role to carry oxygen, nutrients and essential molecules and growth factors into damaged tissue. Then, the angiogenesis and osteogenesis communicated harmoniously together for bone regeneration, because many studies confirmed the crosstalk between bone progenitor cells and endothelial cells. Therefore, the scaffolds containing osteoinductive and angioinductive factors released various types of molecules to stimulate osteogenesis and angiogenesis (Rather et al. 2019). The studies showed that many scaffolds were investigated in the field of bone repair with the purpose of bettering cell growth, adhesion and proliferation, osteogenic differentiation, vascularization, and mechanical properties, but Roseti et al. (2017) reported that the further depth studies will be needed for using the bone tissue engineering scaffolds in clinical application.

\section{Nanomedicine for healing of bone trauma and defects}

One of the most important drawbacks in the healing of open fractures is infection. The failure of the tissue obstruction among the rupture location and the external milieu result 
in bone bacteriological infection and contamination (Broos and Sermon 2004).

Besides, it was proved that Staphylococcus aureus (is a Gram-positive, round-shaped bacterium that is a member of the firmicutes, and it is a usual member of the microbiota of the body) may attack intracellular sites contained by osteoblasts, result in complications in microbial eradication and amplified vulnerability to osteomyelitis subsequent contamination (Join Lambert et al. 2005). The infected fractures need management including medical debridement, antibiotics, and skeletal stabilization. Frequently, antibiotic-contained cement made of polymethylmethacrylate (PMMA) is implanted to harmonize the antibacterial activity (Schade and Roukis 2010). The growth and differentiation of osteoblasts and osteoclasts are controlled by growth factors, cytokines produced in the bone-marrow ECM, and adhesion structures that facilitate cell-cell and cell-ECM communications ( $\mathrm{Lu}$ et al. 2012).

Numerous categories of antibacterial nanoparticles (NPs) and nano-sized carriers for antibiotic delivery have been confirmed to be applicable in curing infectious diseases, containing antibiotic-resistant ones, in vitro and in vivo. For instance, several NPs are able to join to the membrane of microorganisms by electrostatic interface and destruct the unity of the microorganism membrane (Banerjee et al. 2011). Another mechanism is that designed NPs are able to produce massive oxidative stress to microorganisms through free radical construction such as reactive oxygen species
(ROS) and destroy their contamination hazard as it is shown in Fig. 4 (Long et al. 2006).

One of the most frequently used NPs for diminution of infection risk in orthopedic distress is silver (Ag) NPs. Their extensive antibacterial performance is proved. They are extensively applied to remove various bacteria containing S. aureus, Bacillus subtilis, Klebsiella pneumoniae, Pseudomonas aeruginosa, and Escherichia coli.

Polymethylmethacrylate (PMMA)-based bone cement, consisting of Ag NPs (about $50 \mathrm{~nm}$ ), completely prevented the propagation of Staphylococcus epidermidis, methicillinresistant S. epidermidis (MRSE), and methicillin-resistant S. aureus (MRSA), while PMMA bone cement contained $2 \%$ of gentamicin sulfate avoided only the propagation of S. epidermidis (Abid et al. 2017). In additional research, an antibacterial HA NPs scaffold was created, and antibacterial properties were attained by the addition of Ag NPs.

In another study, selenium (Se) NPs were employed to coat a bioactive glass-based structure $\left(\mathrm{SiO}_{2}\right.$ and molar ratio of $\mathrm{P}$ to $\mathrm{Ca}=1 / 5$ ) fabricated by the foam replica technique. The results indicated that this scaffold has antibacterial activity (Fathi-Achachelouei et al. 2019)..

\section{Cell-based combination products with cells from various sources}

Tissue-particular cells such as osteoblasts maybe employed as the cellular constituent of bone transplants. Several kinds
Fig. 4 Toxicity mechanisms of NPs and their ions (e.g., silver and zinc) against bacteria by induce oxidative stress by means of the production of reactive oxygen species (ROS). The ROS is able to conclusively break bacteria (e.g., their membrane, DNA, and mitochondria) culminating in bacterial death (Hajipour et al. 2012)

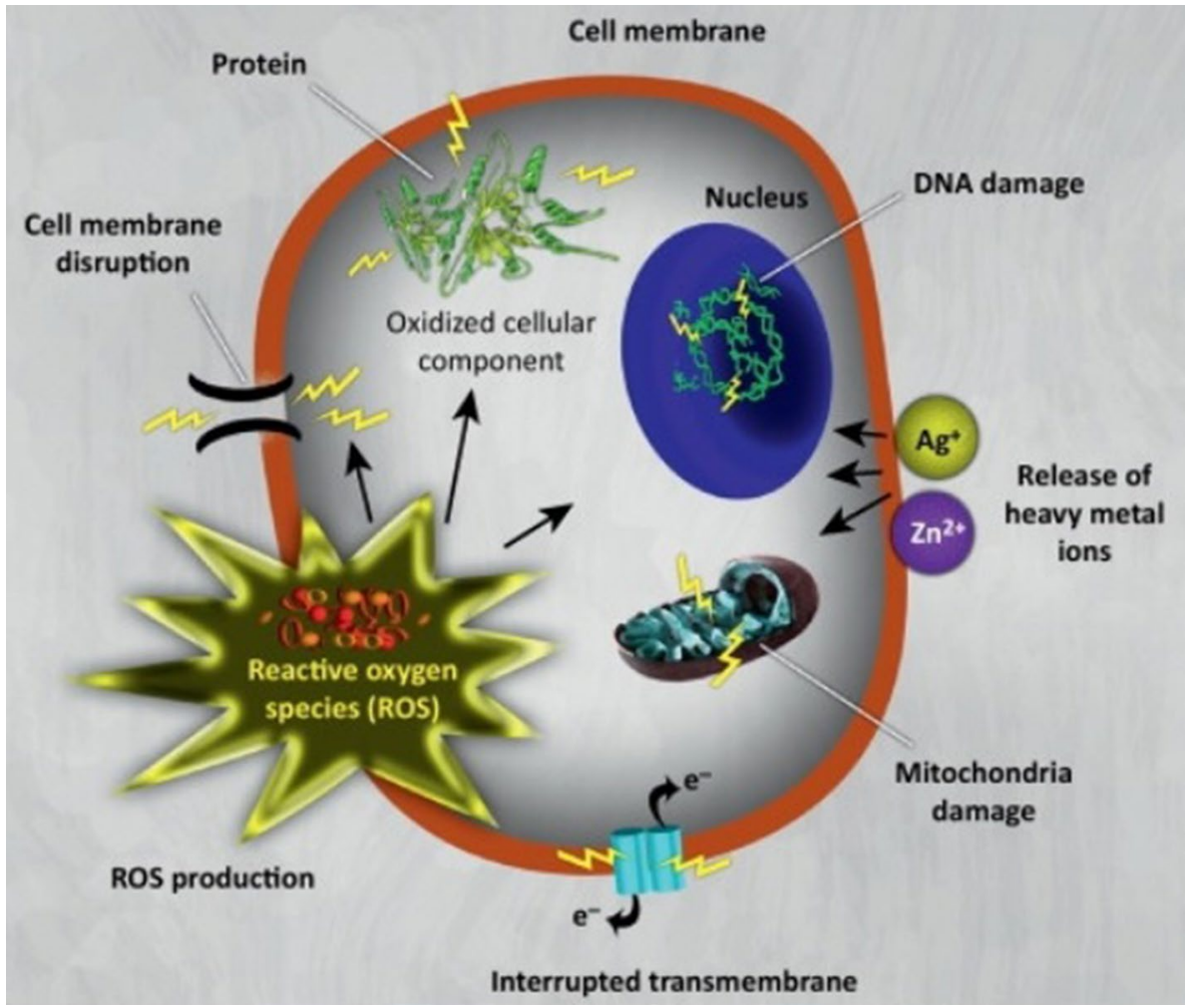


of stem cells have been mostly used through the construction of bone grafts (Omrani et al. 2019). Multipotent adult mesenchymal stem cells (MSCs) show unlimited differentiation capacity into various kinds of cell lineages, containing osteoblasts and chondrocytes (Baksh et al. 2004). Adult MSCs perform as an inducible backup potency for tissue restoration following damage, and have been considered broadly for bone fracture regeneration. MSCs obtained from numerous diverse sources containing bone marrow, synovial membrane, skeletal muscle, and adipose tissue. Cell-based therapy with allogenic BMSCs implants is operative in bone regeneration in different animal bone defect models. In initial clinical studies, autologous BMSCs have been cultured on bio-ceramic scaffold to heal big bone defects. Local transplantation at the defect situate of MSCs led to widespread fusion at 5-7 months after surgery (Cancedda et al. 2003).

Another study indicated bone repair in rabbit skull defects healed with autologous, osteogenically induced adiposederived stem cells (ADSCs) transplanted onto fibronectin-coated polylactic acid scaffold (Di Bella et al. 2008). Additional study showed cranial bone defect regeneration in canine by means of osteogenically induced ADSCs transplanted onto a coral structure (Aimaiti et al. 2011). In a different research, calvarial defects treated through autologous ADSCs/fibrin glue/autologous cancellous bone graft. After 2 months, new bone mineralization and complete calvarial integrity were observed (Lendeckel et al. 2004).

Multipotential synovial membrane-derived MSCs (SMSCs) stromal cells can operate as a healing substitute for focal cartilage damages and have capability to differentiate to osteogenesis. Stimulatingly in a current research, SMSCs from knee joints presented greater osteogenic and adipogenic potential than SMSCs of hip joints (Kristjánsson et al. 2013).

Dental pulp-derived stem cells (DPSCs) have lately being discovered for bone tissue engineering. DPSCs present the low percentages of morbidity, widespread differentiation capacity into chondrogenic, and osteogenic cell lines, and expression of bone markers in vitro and in vivo (d'Aquino et al. 2008). Alginate microsphere DPSCs carrier has the osteogenic potential through detecting improved mineralization and upregulated intensities of osteogenic genes (Moshaverinia et al. 2012). DPSCs seeded/collagen-HA-poly(Llactide-co- $\varepsilon$-caprolactone) scaffold confirmed effective ECM mineralization of osteoblast (Akkouch et al. 2014). Some tissues for instance placenta, umbilical cord blood (UCB) and umbilical cord tissue are different sources of MSCs (Jin et al. 2013). The regenerative capability of RGD-functionalized microporous calcium phosphate cements (CPC) contained UC MSCs and BM MSCs were compared in a rat bone defect model. The results showed comparable great bone inorganic compactness, new bone formation and vascularization in vitro and in vivo (Gan et al. 2018).
Pluripotent human embryonic stem cells (hESCs) are obtained from human blastocysts. Effective differentiation of hESCs into the osteogenic lineage has been confirmed in frequent reports mutually in vitro and in vivo. Actually, following osteogenic stimulation, hESCs demonstrated to retain molecular and fundamental characteristics similar to bone cells by means of the creation of mineralized bone in vitro. Osteogenic cells derived from ESCs seeded on poly(D,L-lactic-co-glycolic acid)/HA scaffold showed substantial in vivo bone construction in immunodeficient mice through subcutaneously seeding (Tang et al. 2012).

Induced pluripotent stem cells (iPSCs) have been originated from adult somatic cells such as skin fibroblast (Kim et al. 2010). IPSCs have the capacity to differentiate to all cell types. IPSCs obtained from embryonic source have the ability to produce MSC-like cells in vitro which presented the capability of more differentiating property to osteoblast cells, whereas similarly indicating osteogenic capacity comparable to that of BMSCs in vivo. Furthermore, in vivo investigations have confirmed that MSC-like cells obtained from iPSCs present the capability to develop mature mineralized construction similar to bone structure (Wu et al. 2017).

Endochondral bone tissue engineering using progenitor cells such as chondroprogenitors has been lately demonstrated. Several researches presented that articular chondrocytes are able to be stimulated to endochondral ossification and generate TGF $\beta-1$ and BMP-2 (Perez et al. 2018). In a study, chondrocyte cell seeded on BMP-2-loaded polycaprolactone (PCL) scaffold which subcutaneously implanted in vivo result in bone formation (Lee and Shin 2007).

\section{Biomimetic fibrous and nonfibrous substitutes}

Bone tissue has a mineralized construction. Biomimetic composite substitute with a mineral constituent were used broadly for bone repair. The mineral component induces structural integrity and osteoconductive properties to the scaffold. HA is frequently used for the reason that has the potential to simulate the natural minerals part of bone. Besides, other calcium phosphate or bioglass were similarly used for their biocompatibility. Using dioxane/water as a solvent, nano-HA/PLLA nanofibers composite scaffolds through TIPS (thermally induced phase separation) technique were fabricated. The high surface area of the nanofibrous permits further the HA to be exposed, which is appropriate for bone tissue regeneration (He et al. 2009).

In another study, HA was incorporated into electrospun nanofibers, then utilized a gelatin-apatite precipitate homogenized in an organic solvent with polylactide-co-caprolactone (PLCL). For the duration of the precipitation reaction, the $\mathrm{Ca} / \mathrm{P}$ proportion was reserved to 1.67 to guarantee stoichiometric apatite fabrication. Just the lowest concentration 
of gelatin-apatite leads to a growth in normal strength (Kim et al. 2006).

Lately, electrodeposition method has been developed that decreases the mineralization time. To demonstrate the flexibility of the technique, electrodeposition has been effectively made on both electrospun PLLA fibers and phaseseparated PLLA fibers. Consequently, electrodeposition confirmed to be a fast and operative method to mineralize a bone tissue scaffold (Wei and Ma 2006). Collagen, in the form of injectable hydrogels, membranes, or sponges, extensively employed for bone tissue regeneration. Individually, as composite with calcium phosphate structures such as HA; Several instances include, collagen/HA/chitosan or collagen/ HA/alginate hydrogels (Teng et al. 2008).

\section{Biomaterial-based 3D cell-printing substitutes}

3D printing employs 3D images of the bone trauma anatomy, usually acquired from computed tomography (CT) scans, using a calculating software, to fabricate a bone graft substitutes (BGS) structure that matches to a bony defect (Burleson and DiPaola 2019). The personalized bone graft substitute form is fabricated using a 3D printer to control the BGS mechanical features and substantial parameters. The composition optimization confirms an improved correspondence among the BGS and the patient's anatomy, permitting the regeneration. Metallic replacements manufactured by titanium are the further most extensively used. Titanium plates are usually employed to immobilize bone parts in jaw operations. 3D printing is similarly being studied for orthopedic purposes: for acetabular ruptures, ankle defects and further bone defects due to bone fracture, spurt fissure of spine, bone cancer and orbital ground repair. The tailored spongy implant printed using $\mathrm{Ti}_{6} \mathrm{Al}_{4} \mathrm{~V}$ presented outstanding physicochemical features and biological function such as biocompatibility, osteogenic property, and bone regeneration (Alvarez and Nakajima 2009). Bioceramics and biopolymers such as polyetheretherketone (PEEK) are currently custom designed, and are presently being investigated at the preclinical phase (Yan et al. 2015). PCL/HA composite is being studied for the repair of gingival recession concomitant with bone and gingival tissue repair (Osathanon et al. 2017).

In a recent study, a mandible bone was repaired via human amniotic fluid-derived stem cell (hAFSC)-laden hydrogel, a mixture of PCL and tricalcium phosphate (TCP), and pluronic F127 (Fig. 5b). The PCL/TCP and hAFSCs mixed with the combination of hydrogel were reproduced in a type I design with a Pluronic F127 impermanent support (Fig. 5c). Subsequently induction of osteogenic differentiation for 28 days (Fig. 5d), they stained the constructions with Alizarin Red S; staining at the surface of the 3D bone constructions showed calcium deposition in the hAFSC laden hydrogel (Fig. 5e).

\section{Bioactive porous polymer/inorganic composites}

The artificial and biodegradable, polymer/inorganic bioactive part compounds are used as bone tissue engineering supports as a result of their formability, bioactive performance and regulating biodegradation kinetics (Rezwan et al. 2006).

Two categories of biodegradable biopolymers are presented: the natural polymers containing polysaccharides such as starch, alginate, chitin/chitosan, hyaluronic acid, proteins for instance collagen, fibrin gels, silk and, as reinforcement, a diversity of bio-fibers including lignocellulosic natural fibers, and the synthetic polymers are used as 3D scaffolds in bone tissue engineering, are saturated poly- $\alpha$-hydroxy esters, containing polylactic acid (PLA) and poly glycolic acid (PGA), as well as polylactic-coglycolide (PLGA) copolymers (Gentile et al. 2014).

PPF (polypropylene fumarate) has been used as an injectable bone substitute scaffold for conducted tissue regeneration. It was similarly utilized as a substrate for osteoblast cultures. The growth of composite substrates adjoining polypropylene fumarate and mineral elements, such as HA or bioglasses, in contrast with the broad investigation works devoted to PLGA and PLA composites (Chen et al. 2012).

Aliphatic polyesters PHAs manufactured through bacteria under unstable progress situations. They are commonly biodegradable (through hydrolysis), biocompatible and thermoprocessable (Lizarraga-Valderrama et al. 2016). These fascinating properties make them suitable for biomedical applications in particular tissue engineering. PHA, principally poly-3-hydroxybutyrate (PHB), copolymers of 3-hydroxybutyrate and 3 hydroxyvalerate (PHBV), poly4-hydroxybutyrate (P4HB), copolymers of 3-hydroxybutyrate and 3-hydroxyhexanoate (PHBHHx) and poly-3-hydroxyoctanoate (PHO) were confirmed to be appropriate for bone tissue regeneration (Ke et al. 2017).

Degradation products of bioglasses, especially the 45S5 Bioglass structure, regulate the gene activation that manages osteogenesis and the fabrication of growth factors (Xynos et al. 2001). HA and silicon have a vital character in the bone mineralization and gene expression, which requires greater than before attention in the substitution of silicon for calcium into HA structure (Arvidson et al. 2011). In vivo results have revealed that bone remineralization into silicondoped HA particles has been significant larger than that pure HA. Bioactive glasses lately have been used as scaffold, filler or coatings of polymers and, as porous constituents, which contains melt-derived and sol-gel-derived bioglasses (Wang and Yeung 2017).

In vivo and in vitro evaluation of crystalline or amorphous calcium phosphates, in bulk, coating, powder, or porous form, induce the attachment, differentiation, and 
a
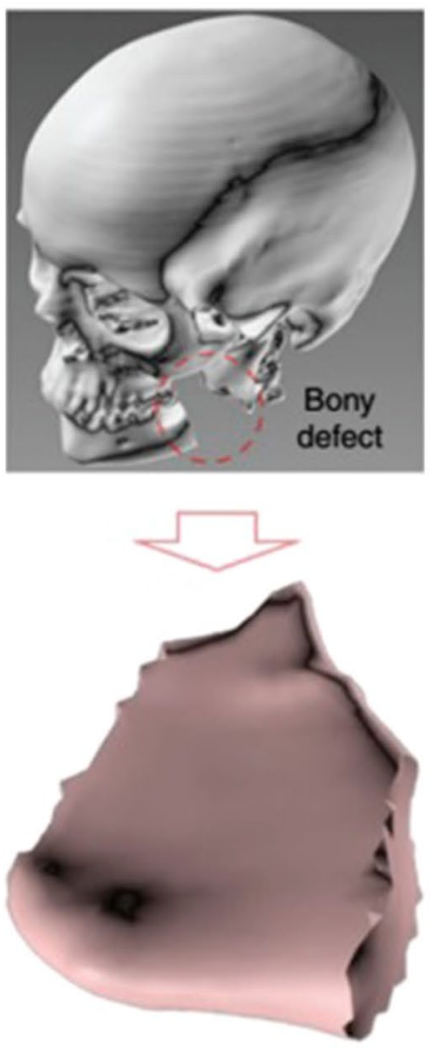

b

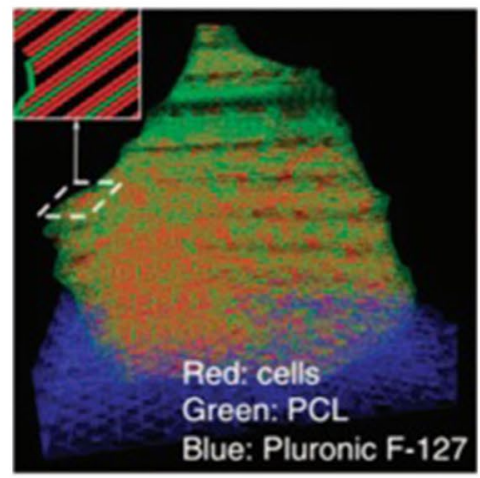

d

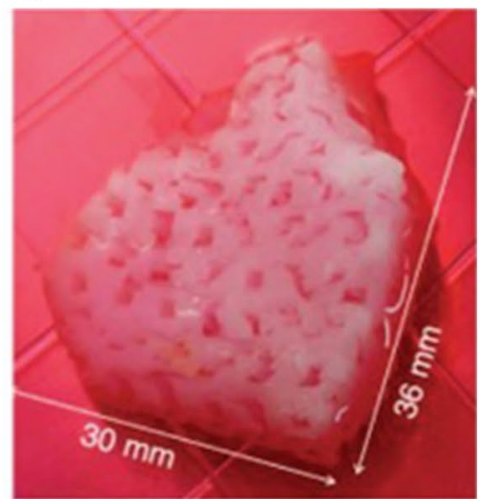

C

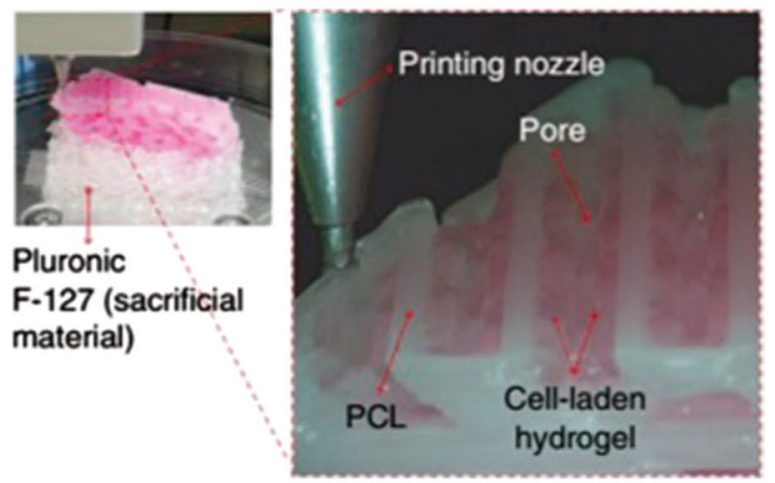

e

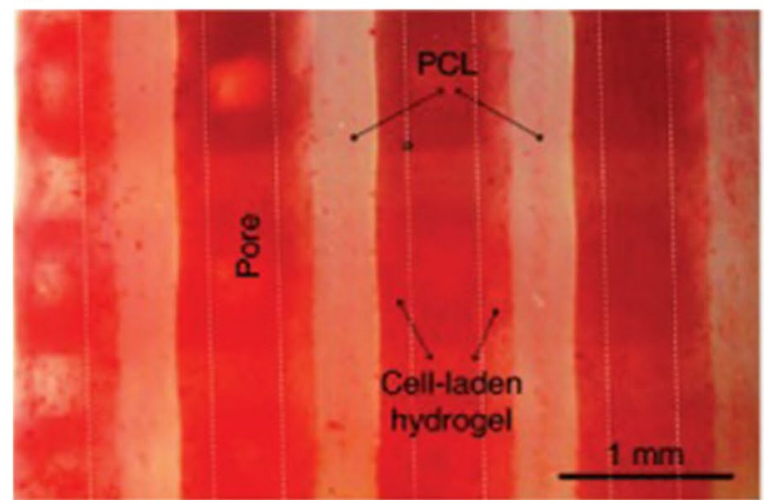

Fig. 5 Mandible bone regeneration. a 3D CAD model identified a mandible bony defect from human CT image data. b Visualized motion program was generated to construct a 3D architecture of the mandible bone defect using CAM software. c 3D printing process using integrated organ printing system. d Photograph of the

proliferation of osteoblasts and mesenchymal stem cells (Rezwan et al. 2006).

\section{Magnetic field and nano-scaffolds with stem cells}

Innovative approaches are using magnetic nanoparticles (MNPs) and magnetic fields to improve bone repair efficiency containing osteogenic improvements by means of magnetic fields, MNPs and magnetic approaches to develop the cells, scaffolds and growth factor conveyances including cell tagging, targeting, designing, and gene modifications (Panseri et al. 2012). The process of scaffolds containing MNPs using magnetic fields and stem cells to improve bone redevelopment were recognized as including the motivation of signaling trails containing MAPK, integrin, BMP and NF-KB (Gonçalves et al. 2016). Static magnetic fields (SMFs), pulsed electromagnetic fields (PEMFs), rotating magnetic fields (RMFs) and alternating electromagnetic fields have the potential to improve the defect healing, bone mineral density, attachment of implants among bone tissue (Xia et al. 2018b). Combination of magnetic fields
3D-printed mandible bone defect construct, which was cultured in osteogenic medium for 28 days. e Osteogenic differentiation of hAFSCs in the printed construct was confirmed by Alizarin Red S staining, indicating calcium deposition (Jang et al. 2018)

with growth factors and signaling factor, magnetically aided freezing and defrosting of stem cells, magnetically aided scaffold and coating constructions are able to improve bone restoration. Animal research presented that SMFs with moderate intensity improved the bone mineral compactness and bone repair (Fitzsimmons et al. 1995).

SMFs may possibly modify cell functions such as the attachment, morphology, proliferation, differentiation, apoptosis, gene expression, in particular osteogenic differentiation for different kinds of cells, containing BMSCs, human osteosarcoma cell lines MG63, human adipose-derived MSCs, and dental pulp stem cells (DPSCs) due to electrodynamic interactions and magneto mechanical interactions (Xia et al. 2018b). Superparamagnetic iron oxide nanoparticles (SPIONs) are encouraging for targeted drug delivery, tissue engineering, hyperthermia, gene therapy, imaging and cell tracking purposes. SPIONs without a magnetic field can improve the tissue repair productivity, be responsible for dynamic mechanical motivations for bone regeneration, encourage osteogenic differentiation of BMSCs, and develop bone healing in vivo (Santhosh and Ulrih 2013). 
In a study, gelatin/SPION-scaffold were implanted in the incisor sockets of rat model which improved bone restoration in comparison to gelatin porous structure control without SPIONs. It is notable that the endocytic SPIONs stimulated the osteogenic and angiogenic performance of the cells result in better bone regeneration (Gu et al. 2013). The aggregation of SPIONs as a result of magnetic fields may change their biological impression. Definitely, decrease in cell uptake followed for the reason that agglomeration of the particles as a result of substantial variations in mutually the size and zeta potential. Furthermore, external magnetic fields may affect the biological properties of SPIONs such as therapeutic/toxic effects. In a research, $\left(\mathrm{Fe}^{2+} / \mathrm{Fe}^{3+}\right)$-doped HA (FeHA) nanoparticles in cultures with osteoblast-like cells in the absence, or presence, of an SMF were investigated. Application of external magnetic field to FeHA lead to a substantial cell growth, proliferation and more osteoblastic activity as a result of the tremendous biological impacts of HA and the partial iron content. Consequently, the variations in the biological characteristic and endocytosis of the cells, created by the MNPs using external magnetic field, may pointedly improve the cell performance and bone renewal abilities (Tampieri et al. 2014). Stem cells have excessive potential for tissue repair. Magnetically labeled cells have the potential application for bone tissue regeneration, containing cell targeting and cell patterning. SPIONs are able to operate as an ideal labeling and tracer tool for MSCs. MNP intake into the cells and make them manageable and manipulated by external magnetic field. In a study implantation of magnetically labeled MSCs were employed to regenerate serious chronic osteochondral traumas, exposure to an external magnetic field, considerably produced new chondrogenic tissues ( $\mathrm{Li}$ et al. 2018).

Dip coating technique was used to fabricate magnetic HA/collagen scaffolds. The magnetic scaffolds support the attachment and proliferation of hBMSCs, and motivate osteoblastic differentiation. The results were along with a different study on MNP-HA magnetic scaffolds.

In another study, nanofibrous $\gamma-\mathrm{Fe}_{2} \mathrm{O}_{3} / \mathrm{HA} /$ polylactic acid was fabricated. This scaffold improved the proliferation of osteoblastic by reason of the SPION integration (Kim et al. 2006). In a current research, an injectable calcium phosphate/SPIONs cement has been developed by mixing with a SPION. Osteogenic differentiation and bone matrix mineral synthesis by the cells was similarly improved two folded in comparison to samples without SPIONs (Xia et al. 2018a). $\mathrm{Fe}_{3} \mathrm{O}_{4}$ nanoparticle/bioactive glass/polycaprolactone $\left(\mathrm{Fe}_{3} \mathrm{O}_{4} / \mathrm{MBG} / \mathrm{PCL}\right)$ scaffolds was fabricated using a $3 \mathrm{D}$ printing method. The results indicate that cell growth on the $\mathrm{Fe}_{3} \mathrm{O}_{4} / \mathrm{MBG} / \mathrm{PCL}$ scaffolds was greater than nonmagnetized control sample (Zhang et al. 2014). In vivo results using rabbit model confirmed that the PCL/FeHA scaffolds were enhanced bone regeneration in comparison to non-magnetized control. SPIONs/nHA and PLA nanofibrous scaffold was implanted in the lumbar transverse defects in rabbit model and then SMF were applied. The MNP scaffold with application of an SMF persuaded more osteogenesis, new bone formation and remodeling in the rabbit defects (Hu et al. 2018). Along with stem cells and scaffolds, growth factors delivering are a vital method in bone tissue regeneration. MNPs have the potential for using as a delivery tool for biological mediators for instance drugs, chemotherapeutics, antibodies, peptide, oligonucleotides, and growth factors through magnetic fields. For example, gene delivery using MNPs possibly will be multifunctional, performing utilities that contain the identification, healing and visualization of the disease at the same time. Consequently, magnetic-based gene delivery is extremely promising method for stem cell therapy (McCarthy et al. 2007).

\section{Bone/biomaterials interface studies}

For the effective integration of implants or scaffolds for tissue regeneration, cell adhesion to biomaterials is a vital necessity. Adjusting cells-scaffolds communications seems of most important to affect succeeding cell biological progressions for instance attachment, proliferation and differentiation (Tormos 2016). Numerous reports show that the adhesion of integrins in bone cells including osteoblasts and osteoclasts to the extracellular matrix is vital through the bone repair (Puleo and Nanci 1999). Bone extracellular matrix proteins arbitrate the biological function of cells through moderating their milieu. Motivation of the attachment, proliferation and differentiation of the bone cells are determined by the part of the superficial characteristics, chemical composition, electrostatic charge, texture, geometrical configuration, roughness and smoothness, of the replacement (Venkatesh and Sen 2017). The ceramic biomaterials may be abrasive and consequently, it is crucial to avoid them in uncontrolled damage neighboring to articular surfaces. Bioglass ionic extracts and surface exchanges stimulate the proliferation and differentiation of osteoblasts and the fabrication of the primary phenotypic biomarkers (Abid et al. 2017, 2016).

The cell activities are regulated by biodegradable polymers with properties such as chemical structure, polymer ratio of PLA or PGA for example, molecular weight and crystallinity. Polymer degradation products for instance catalysts, additives, byproducts and residual monomers that led to an inflammatory reaction and influence the cell attachment, cell survival and proliferation (Puppi et al. 2010). Composite structures present tolerable physiological and mechanical performance such as the characteristics and morphology of cortical and trabecular bone. Signaling factors can be included to bone composites to stimulate cell behavior and favor bone repair. Several factors impact on 
the release of growth factors, for example the surface charge and chemistry of composite, geometry, dimensions, porosity, wettability, crystallinity, the rate of degradation. The growth factor release could be regulated by diffusion, exterior motivation, enzymatic/chemical response (Muzzarelli 2011). The cell attachment to biomaterial and their following performances can be influenced by surface features for instance topography, hydrophobicity, charge, chemistry and special surface energy (Von Recum and Van Kooten 1996). These all affect the conformation, alignment and amounts of adhesion proteins including vitronectin or fibronectin that facilitate the interfaces among cells and biomaterial (Place et al. 2009). Lithography, colloidal particle adsorption, micro-contact printing, novel polymer preparations and self-assembled monolayers are all employed to analyze the interactions among cells and biomaterials at the micro- and nanometer scale (Ma et al. 2007). These methods may be utilized to regulate the topographic properties, micrometer or nanometer ridges, grooves pits, islands, holes. Some studies have revealed improved bone-biomaterial interactions with a high surface roughness. In a study, PLA-polystyrene films with porous of about $45 \mathrm{~nm}$ caused human fetal osteoblasts to proliferate expressively more and attach greatly better than a flat PLA surface (Kochesfahani 2016). Current investigations have employed in vitro self-assembling monolayers containing PEG, $\mathrm{OH}, \mathrm{COOH}, \mathrm{NH}_{2}$ and $\mathrm{CH}_{3}$ groups to assess the consequence of surface chemistry and hydrophilicity on protein adsorption and cell performance such as the attachment strength of MC3T3-E1 preosteoblasts and the medium mineralization. The results show mineralization by cells on $\mathrm{OH}$ and $\mathrm{NH}_{2}$ surfaces is associated with improved alpha 5 beta 1 integrin adhesion and FAK stimulation (Keselowsky et al. 2003). Besides, the experiments approved that osteoblasts adhered and proliferated further on positively charged hydrogels in comparison to neutral or negatively charged ones (Liu et al. 2014).

\section{Conclusions}

This review investigated the bone physiology, different strategies for bone repair and interface studies. The published results provide insightful information for development of new biomaterial-based products. However, there is a vital necessity to investigate the results of all clinical trials. There are several bone repair strategies including bone graft replacements, implantable materials and scaffolds, optimized 3D structure and favored surface properties. Bioactive constituents are necessitated while the bone defects become larger. For this goal, signaling factors, polypeptides and small biomolecules are presently being assessed at the pre-clinical phase. The incorporation of bioactive molecules with novel carriers may result in a developed conveyance of the active molecules at a reliable and useful amount. Besides, cell-based approaches can be utilized for big and complicated bone defects. The efficient clinical treatment demands more controlling phases for future developments.

\section{Compliance with ethical standards}

Conflict of interest Authors did not receive research grants. The authors declare that they have no conflict of interests.

Ethical statement This article does not contain any studies with animals performed by any of the authors.

Open Access This article is distributed under the terms of the Creative Commons Attribution 4.0 International License (http://creativecommons.org/licenses/by/4.0/), which permits unrestricted use, distribution, and reproduction in any medium, provided you give appropriate credit to the original author(s) and the source, provide a link to the Creative Commons license, and indicate if changes were made.

\section{References}

Abid CZ, Jain S, Jackeray R, Chattopadhyay S, Singh H (2017) Formulation and characterization of antimicrobial quaternary ammonium dendrimer in poly (methyl methcarylate) bone cement. J Biomed Mater Res B Appl Biomater 105(3):521-530

Aimaiti A, Saiyiti M, Yun-hai W, Yusufu A, Saiwulaiti Y, Lei C, Shuang-ming S (2011) Therapeutic effect of osteogenically induced adipose derived stem cells on vascular deprivationinduced osteonecrosis of the femoral head in rabbits. Chin J Traumatol 14(4):215-220

Akkouch A, Zhang Z, Rouabhia M (2014) Engineering bone tissue using human dental pulp stem cells and an osteogenic collagenhydroxyapatite-poly (1-lactide-co- $\varepsilon$-caprolactone) scaffold. J Biomater Appl 28(6):922-936

Alvarez K, Nakajima H (2009) Metallic scaffolds for bone regeneration. Materials 2(3):790-832

Ansari M, Eshghanmalek M (2019) Biomaterials for repair and regeneration of the cartilage tissue. Bio-Design Manuf 2(1):41-49

Ansari M, Moztarzadeh F (2012) Effect of the synthesis parameters on the properties of biphasic $\mathrm{Ca}(\mathrm{OH})$-HA nanopowders for tissue engineering applications. Iran J Pharm Sci 8(1):335-342

Ansari M, Naghib S, Moztarzadeh F, Salati A (2011) Synthesis and characterisation of hydroxyapatite-calcium hydroxide for dental composites. Ceramics-Silikáty 55(2):123-126

Ansari M, Kordestani SS, Nazralizadeh S, Eslami H (2018) Biodegradable cell-seeded collagen based polymer scaffolds for wound healing and skin reconstruction. J Macromol Sci Part B 57(2):100-109

Arvidson K, Abdallah B, Applegate L, Baldini N, Cenni E, GomezBarrena E, Granchi D, Kassem M, Konttinen Y, Mustafa K (2011) Bone regeneration and stem cells. J Cell Mol Med 15(4):718-746

Baksh D, Song L, Tuan R (2004) Adult mesenchymal stem cells: characterization, differentiation, and application in cell and gene therapy. J Cell Mol Med 8(3):301-316

Banerjee I, Pangule RC, Kane RS (2011) Antifouling coatings: recent developments in the design of surfaces that prevent 
fouling by proteins, bacteria, and marine organisms. Adv Mater 23(6):690-718

Bateman J, Intini G, Margarone J, Goodloe S, Bush P, Lynch SE, Dziak $R$ (2005) Platelet-derived growth factor enhancement of two alloplastic bone matrices. J Periodontol 76(11):1833-1841

Behzadi S, Luther GA, Harris MB, Farokhzad OC, Mahmoudi M (2017) Nanomedicine for safe healing of bone trauma: opportunities and challenges. Biomaterials 146:168-182

Bessa PC, Casal M, Reis R (2008) Bone morphogenetic proteins in tissue engineering: the road from laboratory to clinic, part II (BMP delivery). J Tissue Eng Regen Med 2(2-3):81-96

Bhatnagar RS, Qian JJ, Wedrychowska A, Sadeghi M, Wu YM, Smith N (1999) Design of biomimetic habitats for tissue engineering with P-15, a synthetic peptide analogue of collagen. Tissue Eng 5(1):53-65

Bostrom MP, Seigerman DA (2005) The clinical use of allografts, demineralized bone matrices, synthetic bone graft substitutes and osteoinductive growth factors: a survey study. HSS J 1(1):9-18

Boyle WJ, Simonet WS, Lacey DL (2003) Osteoclast differentiation and activation. Nature 423(6937):337

Broos P, Sermon A (2004) From unstable internal fixation to biological osteosynthesis a historical overview of operative fracture treatment. Acta Chir Belg 104(4):396-400

Bruder SP, Fink DJ, Caplan AI (1994) Mesenchymal stem cells in bone development, bone repair, and skeletal regeneration therapy. J Cell Biochem 56(3):283-294

Burg KJ, Porter S, Kellam JF (2000) Biomaterial developments for bone tissue engineering. Biomaterials 21(23):2347-2359

Burleson J, DiPaola C (2019) 3D printing in spine surgery. In: 3D printing in orthopaedic surgery. Elsevier, Amsterdam, pp 105-122

Cancedda R, Dozin B, Giannoni P, Quarto R (2003) Tissue engineering and cell therapy of cartilage and bone. Matrix Biol 22(1):81-91

Chen X, Ou J, Kang Y, Huang Z, Zhu H, Yin G, Wen H (2008) Synthesis and characteristics of monticellite bioactive ceramic. J Mater Sci Mater Med 19(3):1257-1263

Chen Q, Zhu C, Thouas GA (2012) Progress and challenges in biomaterials used for bone tissue engineering: bioactive glasses and elastomeric composites. Prog Biomater 1(1):2

d'Aquino R, Papaccio G, Laino G, Graziano A (2008) Dental pulp stem cells: a promising tool for bone regeneration. Stem Cell Rev 4(1):21-26

Di Bella C, Farlie P, Penington AJ (2008) Bone regeneration in a rabbit critical-sized skull defect using autologous adipose-derived cells. Tissue Eng Part A 14(4):483-490

Diba M, Goudouri O-M, Tapia F, Boccaccini AR (2014) Magnesiumcontaining bioactive polycrystalline silicate-based ceramics and glass-ceramics for biomedical applications. Curr Opin Solid State Mater Sci 18(3):147-167

Dimitriou R, Tsiridis E, Giannoudis PV (2005) Current concepts of molecular aspects of bone healing. Injury 36(12):1392-1404

Dziadek M, Stodolak-Zych E, Cholewa-Kowalska K (2017) Biodegradable ceramic-polymer composites for biomedical applications: a review. Mater Sci Eng C 71:1175-1191

Ekholm E, Tommila M, Forsback A-P, Märtson M, Holmbom J, Ääritalo V, Finnberg C, Kuusilehto A, Salonen J, Yli-Urpo A (2005) Hydroxyapatite coating of cellulose sponge does not improve its osteogenic potency in rat bone. Acta Biomater 1(5):535-544

Eslami H, Lisar HA, Kashi TSJ, Tahriri M, Ansari M, Rafiei T, Bastami F, Shahin-Shamsabadi A, Abbas FM, Tayebi L (2018) Poly (lactic-co-glycolic acid)(PLGA)/TiO 2 nanotube bioactive composite as a novel scaffold for bone tissue engineering: in vitro and in vivo studies. Biologicals 53:51-62

Fathi-Achachelouei M, Knopf-Marques H, Riberio de Silva CE, Barthès JGD, Bat E, Tezcaner A, Vrana NE (2019) Use of nanoparticles in tissue engineering and regenerative medicine. Front Bioeng Biotechnol 7:113
Fitzsimmons RJ, Ryaby JT, Mohan S, Magee FP, Baylink DJ (1995) Combined magnetic fields increase insulin-like growth factor-II in TE-85 human osteosarcoma bone cell cultures. Endocrinology 136(7):3100-3106

Franz Odendaal TA, Hall BK, Witten PE (2006) Buried alive: how osteoblasts become osteocytes. Dev Dyn 235(1):176-190

Gan D, Liu M, Xu T, Wang K, Tan H, Lu X (2018) Chitosan/biphasic calcium phosphate scaffolds functionalized with BMP-2-encapsulated nanoparticles and RGD for bone regeneration. J Biomed Mater Res Part A 106(10):2613-2624

Gentile P, Chiono V, Carmagnola I, Hatton P (2014) An overview of poly (lactic-co-glycolic) acid (PLGA)-based biomaterials for bone tissue engineering. Int J Mol Sci 15(3):3640-3659

Giannoudis PV, Dinopoulos H, Tsiridis E (2005) Bone substitutes: an update. Injury 36(3):S20-S27

Gonçalves A, Rodrigues MT, Reis R, Gomes ME (2016) Bioengineered strategies for tendon regeneration. In: In situ tissue regeneration. Elsevier, Amsterdam, pp 275-293

Gu W, Wu C, Chen J, Xiao Y (2013) Nanotechnology in the targeted drug delivery for bone diseases and bone regeneration. Int $\mathrm{J}$ Nanomed 8:2305

Haidar ZS, Hamdy RC, Tabrizian M (2009) Delivery of recombinant bone morphogenetic proteins for bone regeneration and repair. Part B: delivery systems for BMPs in orthopaedic and craniofacial tissue engineering. Biotechnol Lett 31(12):1825-1835

Hajipour MJ, Fromm KM, Ashkarran AA, de Aberasturi DJ, de Larramendi IR, Rojo T, Serpooshan V, Parak WJ, Mahmoudi M (2012) Antibacterial properties of nanoparticles. Trends Biotechnol 30(10):499-511

He L, Zhang Y, Zeng X, Quan D, Liao S, Zeng Y, Lu J, Ramakrishna S (2009) Fabrication and characterization of poly (L-lactic acid) 3D nanofibrous scaffolds with controlled architecture by liquidliquid phase separation from a ternary polymer-solvent system. Polymer 50(16):4128-4138

Helminen AO, Korhonen H, Seppälä JV (2002) Cross-linked poly ( $\varepsilon$-caprolactone/d, l-lactide) copolymers with elastic properties. Macromol Chem Phys 203(18):2630-2639

Ho-Shui-Ling A, Bolander J, Rustom LE, Johnson AW, Luyten FP, Picart C (2018) Bone regeneration strategies: engineered scaffolds, bioactive molecules and stem cells current stage and future perspectives. Biomaterials 180:143-162

Hu S, Zhou Y, Zhao Y, Xu Y, Zhang F, Gu N, Ma J, Reynolds MA, Xia $\mathrm{Y}, \mathrm{Xu} \mathrm{HH}$ (2018) Enhanced bone regeneration and visual monitoring via superparamagnetic iron oxide nanoparticle scaffold in rats. J Tissue Eng Regen Med 12(4):e2085-e2098

Hu C, Ashok D, Nisbet DR, Gautam V (2019) Bioinspired surface modification of orthopedic implants for bone tissue engineering. Biomaterials 219:119366

Jang J, Park JY, Gao G, Cho D-W (2018) Biomaterials-based 3D cell printing for next-generation therapeutics and diagnostics. Biomaterials 156:88-106

Jin H, Bae Y, Kim M, Kwon S-J, Jeon H, Choi S, Kim S, Yang Y, Oh W, Chang J (2013) Comparative analysis of human mesenchymal stem cells from bone marrow, adipose tissue, and umbilical cord blood as sources of cell therapy. Int J Mol Sci 14(9):17986-18001

Jin G, He R, Sha B, Li W, Qing H, Teng R, Xu F (2018) Electrospun three-dimensional aligned nanofibrous scaffolds for tissue engineering. Mater Sci Eng C 92:995-1005

Join Lambert OF, Ezine S, Le Monnier A, Jaubert F, Okabe M, Berche P, Kayal S (2005) Listeria monocytogenes-infected bone marrow myeloid cells promote bacterial invasion of the central nervous system. Cell Microbiol 7(2):167-180

Kalantari E, Naghib SM (2019) A comparative study on biological properties of novel nanostructured monticellite-based composites with hydroxyapatite bioceramic. Mater Sci Eng C 98:1087-1096 
Kalantari E, Naghib SM, Reza Naimi-Jamal M, Mozafari M (2017) Green solvent-based sol-gel synthesis of monticellite nanoparticles: a rapid and efficient approach. J Sol-Gel Sci Technol 84(1):87-95

Kalantari E, Naghib SM, Naimi-Jamal MR, Aliahmadi A, Iravani NJ, Mozafari M (2018a) Nanostructured monticellite for tissue engineering applications-part I: microstructural and physicochemical characteristics. Ceram Int 44(11):12731-12738

Kalantari E, Naghib SM, Iravani NJ, Aliahmadi A, Naimi-Jamal MR, Mozafari M (2018b) Nanostructured monticellite for tissue engineering applications - part II: molecular and biological characteristics. Ceram Int 44(12): 14704-14711

Kalantari E, Naghib SM, Naimi-Jamal MR, Esmaeili R, Majidzadeh-A K, Mozafari M (2018c) Nanostructured monticellite: an emerging player in tissue engineering. Mater Today Proc 5(7, Part 3):15744-15753

Kalantari E, Naghib SM, Iravani NJ, Esmaeili R, Naimi-Jamal MR, Mozafari M (2019) Biocomposites based on hydroxyapatite matrix reinforced with nanostructured monticellite $\left(\mathrm{CaMgSiO}_{4}\right)$ for biomedical application: synthesis, characterization, and biological studies. Mater Sci Eng C 105:109912

Ke Y, Zhang X, Ramakrishna S, He L, Wu G (2017) Reactive blends based on polyhydroxyalkanoates: preparation and biomedical application. Mater Sci Eng C 70:1107-1119

Keselowsky BG, Collard DM, García AJ (2003) Surface chemistry modulates fibronectin conformation and directs integrin binding and specificity to control cell adhesion. J Biomed Mater Res Part A 66(2):247-259

Kim HW, Lee HH, Knowles J (2006) Electrospinning biomedical nanocomposite fibers of hydroxyapatite/poly (lactic acid) for bone regeneration. J Biomed Mater Res Part A 79(3):643-649

Kim K, Doi A, Wen B, Ng K, Zhao R, Cahan P, Kim J, Aryee M, Ji H, Ehrlich L (2010) Epigenetic memory in induced pluripotent stem cells. Nature 467(7313):285

Kochesfahani SH (2016) Improving PLA-based material for FDM 3D-printers using minerals (principles and method development). SPE ANTEC, Indianapolis, pp 1598-1614

Kristjánsson B, Mabey T, Yuktanandana P, Parkpian V, Honsawek S (2013) Mesenchymal stem cells for regeneration of cartilage lesions: focus on knee osteoarthritis. Thai J Orthop Surg 37(2-4):67-78

Kular J, Tickner J, Chim SM, Xu J (2012) An overview of the regulation of bone remodelling at the cellular level. Clin Biochem 45(12):863-873

Lalzawmliana V, Anand A, Roy M, Kundu B, Nandi SK (2019) Mesoporous bioactive glasses for bone healing and biomolecules delivery. Mater Sci Eng C:110180

Lee S-H, Shin H (2007) Matrices and scaffolds for delivery of bioactive molecules in bone and cartilage tissue engineering. Adv Drug Deliv Rev 59(4-5):339-359

Lendeckel S, Jödicke A, Christophis P, Heidinger K, Wolff J, Fraser JK, Hedrick MH, Berthold L, Howaldt H-P (2004) Autologous stem cells (adipose) and fibrin glue used to treat widespread traumatic calvarial defects: case report. J Cranio-Maxillofac Surg 32(6):370-373

Li Y, Ye D, Li M, Ma M, Gu N (2018) Adaptive materials based on iron oxide nanoparticles for bone regeneration. ChemPhysChem 19(16):1965-1979

Lim J, You M, Li J, Li Z (2017) Emerging bone tissue engineering via polyhydroxyalkanoate (PHA)-based scaffolds. Mater Sci Eng C 79:917-929

Liu D, Wang T, Liu X, Tong Z (2014) Cell proliferation and cell sheet detachment from the positively and negatively charged nanocomposite hydrogels. Biopolymers 101(1):58-65

Lizarraga-Valderrama L, Panchal B, Thomas C, Boccaccini A, Roy I (2016) Biomedical applications of polyhydroxyalkanoates.
Biomaterials from nature for advanced devices and therapies, pp 339-383

Long TC, Saleh N, Tilton RD, Lowry GV, Veronesi B (2006) Titanium dioxide (P25) produces reactive oxygen species in immortalized brain microglia (BV2): implications for nanoparticle neurotoxicity. Environ Sci Technol 40(14):4346-4352

Lu P, Weaver VM, Werb Z (2012) The extracellular matrix: a dynamic niche in cancer progression. J Cell Biol 196(4):395-406

Luginbuehl V, Meinel L, Merkle HP, Gander B (2004) Localized delivery of growth factors for bone repair. Eur J Pharm Biopharm 58(2):197-208

Ma Z, Mao Z, Gao C (2007) Surface modification and property analysis of biomedical polymers used for tissue engineering. Coll Surf B Biointerfaces 60(2):137-157

McCarthy JR, Kelly KA, Sun EY, Weissleder R (2007) Targeted delivery of multifunctional magnetic nanoparticles. Nanomedicine $2: 153-167$

Moshaverinia A, Chen C, Akiyama K, Ansari S, Xu X, Chee WW, Schricker SR, Shi S (2012) Alginate hydrogel as a promising scaffold for dental-derived stem cells: an in vitro study. J Mater Sci Mater Med 23(12):3041-3051

Muzzarelli RA (2011) Chitosan composites with inorganics, morphogenetic proteins and stem cells, for bone regeneration. Carbohyd Polym 83(4):1433-1445

Naghib SM, Ansari M, Pedram A, Moztarzadeh F, Feizpour A, Mozafari M (2012) Bioactivation of 304 stainless steel surface through 45S5 bioglass coating for biomedical applications. Int J Electrochem Sci 7:2890-2903

Nickel J, Kotzsch A, Sebald W, Mueller TD (2005) A single residue of GDF- 5 defines binding specificity to BMP receptor IB. J Mol Biol 349(5):933-947

Noble BS, Reeve J (2000) Osteocyte function, osteocyte death and bone fracture resistance. Mol Cell Endocrinol 159(1-2):7-13

Omrani MM, Kiaie N, Ansari M, Kordestani SS (2016) Enhanced protein adsorption, cell attachment, and neural differentiation with the help of amine functionalized polycaprolactone scaffolds. J Macromol Sci Part B 55(6):617-626

Omrani MM, Ansari M, Kordestani SS, Kiaie N, Salati A (2019) Enhanced bone marrow stem cell attachment and differentiation on PCL/CNT substrate. Inorganic and Nano-Metal Chemistry, pp $1-7$

Osathanon T, Chanjavanakul P, Kongdecha P, Clayhan P, Huynh NC-N (2017) Polycaprolactone-based biomaterials for guided tissue regeneration membrane. Periodontitis-a useful reference successful. InTech, pp 171-188

Pajarinen J, Lin T, Gibon E, Kohno Y, Maruyama M, Nathan K, Lu L, Yao Z, Goodman SB (2019) Mesenchymal stem cell-macrophage crosstalk and bone healing. Biomaterials 196:80-89

Pakulska MM (2016) Combined delivery of chondroitinase ABC $(\mathrm{ChABC})$ and stromal cell derived factor $1 \alpha(\mathrm{SDF} 1 \alpha)$ for spinal cord regeneration

Panseri S, Cunha C, D’Alessandro T, Sandri M, Russo A, Giavaresi G, Marcacci M, Hung CT, Tampieri A (2012) Magnetic hydroxyapatite bone substitutes to enhance tissue regeneration: evaluation in vitro using osteoblast-like cells and in vivo in a bone defect. PLoS One 7(6): e38710

Perez JR, Kouroupis D, Li DJ, Best TM, Kaplan L, Correa D (2018) Tissue engineering and cell-based therapies for fractures and bone defects. Front Bioeng Biotechnol 6:105

Place ES, Evans ND, Stevens MM (2009) Complexity in biomaterials for tissue engineering. Nat Mater 8(6):457

Poehling S, Pippig SD, Hellerbrand K, Siedler M, Schütz A, Dony C (2006) Superior effect of MD05, beta-tricalcium phosphate coated with recombinant human growth/differentiation factor-5, compared to conventional bone substitutes in the rat calvarial defect model. J Periodontol 77(9):1582-1590 
Portale AA, Booth BE, Halloran BP, Morris R (1984) Effect of dietary phosphorus on circulating concentrations of 1,25-dihydroxyvitamin D and immunoreactive parathyroid hormone in children with moderate renal insufficiency. J Clin Investig 73(6):1580-1589

Puleo D, Nanci A (1999) Understanding and controlling the boneimplant interface. Biomaterials 20(23-24):2311-2321

Puppi D, Chiellini F, Piras A, Chiellini E (2010) Polymeric materials for bone and cartilage repair. Prog Polym Sci 35(4):403-440

Qiu Z-Y, Cui Y, Wang X-M (2019) Natural bone tissue and its biomimetic. In: Mineralized collagen bone graft substitutes. Elsevier, Amsterdam, pp 1-22

Rather HA, Jhala D, Vasita R (2019) Dual functional approaches for osteogenesis coupled angiogenesis in bone tissue engineering. Mater Sci Eng C 103:109761

Rezwan K, Chen Q, Blaker J, Boccaccini AR (2006) Biodegradable and bioactive porous polymer/inorganic composite scaffolds for bone tissue engineering. Biomaterials 27(18):3413-3431

Roseti L, Parisi V, Petretta M, Cavallo C, Desando G, Bartolotti I, Grigolo B (2017) Scaffolds for bone tissue engineering: state of the art and new perspectives. Mater Sci Eng C 78:1246-1262

Roshanbinfar K, Ansari M (2013) Investigating of mechanical and biological properties of porous hydroxyapatite scaffolds produced by novel shake gel casting method. J Biomater Tissue Eng 3(3):284-288

Samavedi S, Whittington AR, Goldstein AS (2013) Calcium phosphate ceramics in bone tissue engineering: a review of properties and their influence on cell behavior. Acta Biomater 9(9):8037-8045

Santhosh PB, Ulrih NP (2013) Multifunctional superparamagnetic iron oxide nanoparticles: promising tools in cancer theranostics. Cancer Lett 336(1):8-17

Sarin S, Rekhi A (2016) Bioactive glass: a potential next generation biomaterial. SRM J Res Dent Sci 7(1):27

Schade VL, Roukis TS (2010) The role of polymethylmethacrylate antibiotic-loaded cement in addition to debridement for the treatment of soft tissue and osseous infections of the foot and ankle. J Foot Ankle Surg 49(1):55-62

Schindeler A, McDonald MM, Bokko P, Little DG (2008) Bone remodeling during fracture repair: the cellular picture. Paper presented at the seminars in cell and developmental biology

Sheikh Z, Hamdan N, Abdallah M-N, Glogauer M, Grynpas M (2019) Natural and synthetic bone replacement graft materials for dental and maxillofacial applications. In: Advanced dental biomaterials. Elsevier, Amsterdam, pp 347-376

Sikavitsas VI, Temenoff JS, Mikos AG (2001) Biomaterials and bone mechanotransduction. Biomaterials 22(19):2581-2593

Solchaga LA, Hee CK, Roach S, Snel LB (2012) Safety of recombinant human platelet-derived growth factor-BB in Augment ${ }^{\circledR}$ Bone Graft. J Tissue Eng 3(1):2041731412442668

Standring S (2016) Gray's anatomy: the anatomical basis of clinical practice, 41 st edn. Elsevier, Amsterdam

Stumpf TR, Yang X, Zhang J, Cao X (2018) In situ and ex situ modifications of bacterial cellulose for applications in tissue engineering. Mater Sci Eng C 82:372-383

Tampieri A, Iafisco M, Sandri M, Panseri S, Cunha C, Sprio S, Savini E, Uhlarz M, Herrmannsdörfer T (2014) Magnetic bioinspired hybrid nanostructured collagen-hydroxyapatite scaffolds supporting cell proliferation and tuning regenerative process. ACS Appl Mater Interfaces 6(18):15697-15707

Tang M, Chen W, Weir MD, Thein-Han W, Xu HH (2012) Human embryonic stem cell encapsulation in alginate microbeads in macroporous calcium phosphate cement for bone tissue engineering. Acta Biomater 8(9):3436-3445

Teng SH, Lee EJ, Wang P, Shin DS, Kim HE (2008) Three-layered membranes of collagen/hydroxyapatite and chitosan for guided bone regeneration. J Biomed Mater Res Part B Appl Biomater 87(1):132-138

Teti A (2011) Bone development: overview of bone cells and signaling. Curr Osteoporos Rep 9(4):264

Tormos CJ (2016) Improved stem cell retention and mechanical stability in a chitosan-gelatin hydrogel. Oklahoma State University, Stillwater

Türk S, Altınsoy İ, Efe GÇ, Ipek M, Özacar M, Bindal C (2019) Effect of solution and calcination time on sol-gel synthesis of hydroxyapatite. J Bionic Eng 16(2):311-318

Uskokovic V, Janković-Častvan I, Wu V (2019) Bone mineral crystallinity governs the orchestration of ossification and resorption during bone remodeling. ACS Biomater Sci Eng. https://doi. org/10.1021/acsbiomaterials.9b00255

Vaidya R, Sethi A, Bartol S, Jacobson M, Coe C, Craig JG (2008) Complications in the use of rhBMP-2 in PEEK cages for interbody spinal fusions. Clin Spine Surg 21(8):557-562

Venkatesh K, Sen D (2017) Mesenchymal stem cells as a source of dopaminergic neurons: a potential cell based therapy for Parkinson's disease. Curr Stem Cell Res Therapy 12(4):326-347

Von Recum A, Van Kooten T (1996) The influence of micro-topography on cellular response and the implications for silicone implants. J Biomater Sci Polym Ed 7(2):181-198

Wang W, Yeung KW (2017) Bone grafts and biomaterials substitutes for bone defect repair: a review. Bioact Mater 2(4):224-247

Wang Y, Azaïs T, Robin M, Vallée A, Catania C, Legriel P, PehauArnaudet G, Babonneau F, Giraud-Guille M-M, Nassif N (2012) The predominant role of collagen in the nucleation, growth, structure and orientation of bone apatite. Nat Mater 11(8):724

Wang D, Jang J, Kim K, Kim J, Park CB (2019) “Tree to Bone": ligninpolycaprolactone nanofibers for hydroxyapatite biomineralization. Biomacromolecules. https://doi.org/10.1021/acs.bioma c. $9 \mathrm{~b} 00451$

Wei G, Ma PX (2006) Macroporous and nanofibrous polymer scaffolds and polymer/bone-like apatite composite scaffolds generated by sugar spheres. J Biomed Mater Res Part A 78(2):306-315

Wu Q, Yang B, Hu K, Cao C, Man Y, Wang P (2017) Deriving osteogenic cells from induced pluripotent stem cells for bone tissue engineering. Tissue Eng Part B Rev 23(1):1-8

Xia Y, Chen H, Zhang F, Wang L, Chen B, Reynolds MA, Ma J, Schneider A, Gu N, Xu HH (2018a) Injectable calcium phosphate scaffold with iron oxide nanoparticles to enhance osteogenesis via dental pulp stem cells. Artif Cells Nanomed Biotechnol 46(sup1):423-433

Xia Y, Sun J, Zhao L, Zhang F, Liang X-J, Guo Y, Weir MD, Reynolds MA, Gu N, Xu HH (2018b) Magnetic field and nano-scaffolds with stem cells to enhance bone regeneration. Biomaterials 183:151-170

Xynos ID, Edgar AJ, Buttery LD, Hench LL, Polak JM (2001) Geneexpression profiling of human osteoblasts following treatment with the ionic products of Bioglass ${ }^{\circledR} 45 \mathrm{~S} 5$ dissolution. J Biomed Mater Res 55(2):151-157

Yan L-P, Oliveira JM, Oliveira AL, Reis RL (2015) Current concepts and challenges in osteochondral tissue engineering and regenerative medicine. ACS Biomater Sci Eng 1(4):183-200

Yi H, Rehman FU, Zhao C, Liu B, He N (2016) Recent advances in nano scaffolds for bone repair. Bone Res 4:16050

Zhang D, Kandadai MA, Cech J, Roth S, Curran SA (2006) Poly (L-lactide)(PLLA)/multiwalled carbon nanotube (MWCNT) composite: characterization and biocompatibility evaluation. J Phys Chem B 110(26):12910-12915

Zhang J, Zhao S, Zhu M, Zhu Y, Zhang Y, Liu Z, Zhang C (2014) 3D-printed magnetic $\mathrm{Fe}_{3} \mathrm{O}_{4} / \mathrm{MBG} / \mathrm{PCL}$ composite scaffolds with 
multifunctionality of bone regeneration, local anticancer drug delivery and hyperthermia. J Mater Chem B 2(43):7583-7595

Zheng Z, Yin W, Zara JN, Li W, Kwak J, Mamidi R, Lee M, Siu RK, Ngo R, Wang J (2010) The use of BMP-2 coupled-nanosilverPLGA composite grafts to induce bone repair in grossly infected segmental defects. Biomaterials 31(35):9293-9300
Publisher's Note Springer Nature remains neutral with regard to jurisdictional claims in published maps and institutional affiliations. 